\title{
Genome sequence and transcriptome analyses of the thermophilic zygomycete fungus Rhizomucor miehei
}

Peng Zhou ${ }^{1 \dagger}$, Guoqiang Zhang ${ }^{2 \dagger}$, Shangwu Chen ${ }^{1}$, Zhengqiang Jiang ${ }^{1 *}$, Yanbin Tang ${ }^{1}$, Bernard Henrissat ${ }^{3,4}$, Qiaojuan Yan ${ }^{5}$, Shaoqing Yang ${ }^{1}$, Chin-Fu Chen ${ }^{6}$, Bing Zhang ${ }^{2^{*}}$ and Zhenglin Du ${ }^{2}$

\begin{abstract}
Background: The zygomycete fungi like Rhizomucor miehei have been extensively exploited for the production of various enzymes. As a thermophilic fungus, $R$. miehei is capable of growing at temperatures that approach the upper limits for all eukaryotes. To date, over hundreds of fungal genomes are publicly available. However, Zygomycetes have been rarely investigated both genetically and genomically.

Results: Here, we report the genome of $R$. miehei CAU432 to explore the thermostable enzymatic repertoire of this fungus. The assembled genome size is 27.6 -million-base $(\mathrm{Mb})$ with 10,345 predicted protein-coding genes. Even being thermophilic, the $\mathrm{G}+\mathrm{C}$ contents of fungal whole genome (43.8\%) and coding genes (47.4\%) are less than $50 \%$. Phylogenetically, R. miehei is more closerly related to Phycomyces blakesleeanus than to Mucor circinelloides and Rhizopus oryzae. The genome of $R$. miehei harbors a large number of genes encoding secreted proteases, which is consistent with the characteristics of $R$. miehei being a rich producer of proteases. The transcriptome profile of R. miehei showed that the genes responsible for degrading starch, glucan, protein and lipid were highly expressed.

Conclusions: The genome information of $R$. miehei will facilitate future studies to better understand the mechanisms of fungal thermophilic adaptation and the exploring of the potential of $R$. miehei in industrial-scale production of thermostable enzymes. Based on the existence of a large repertoire of amylolytic, proteolytic and lipolytic genes in the genome, $R$. miehei has potential in the production of a variety of such enzymes.
\end{abstract}

Keywords: Rhizomucor miehei, Genome, Transcriptome, Thermophilic fungus, Thermostable enzymes

\section{Background}

Of the predicted about 0.6 million fungal species, only 44,368 have been catalogued [1]. Seven major groups ("Phyla"), 10 subphyla, 35 classes, 12 subclasses and 129 orders are recognized within the fungal kingdom [2]. Thermophilic fungi in general have a maximum growth temperature at or above $40^{\circ} \mathrm{C}$ [3]. This is in contrast to most other mesophilic fungi by displaying a maximum temperature less than $35^{\circ} \mathrm{C}$. Among more than forty thermophilic fungi which have been studied [3], five (viz.

\footnotetext{
* Correspondence: zhqjiang@cau.edu.cn; zhangbing@big.ac.cn

${ }^{\dagger}$ Equal contributors

'Department of Biotechnology, College of Food Science and Nutritional Engineering, China Agricultural University, Beijing 100083, China

${ }^{2}$ Core Genomic Facility, Beijing Institute of Genomics, Chinese Academy of Sciences, Beijing 100101, China

Full list of author information is available at the end of the article
}

Rhizomucor miehei, Rhizomucor nainitalensis, Rhizomucor pusillus, Rhizopus microsporus, Rhizopus rhizopodiformis) belong to Zygomycetes. The genera Rhizomucor, Mucor and Rhizopus are classified under the family Mucoraceae in the order Mucorales, which is a primitive and early divergent group of fungi. The genus Rhizomucor consists of Mucor-like fungi that produce nonapophysate sporangia and branched sporangiophores but unlike Mucor they form rhizoids. Rhizomucor species are clearly distinct from Mucor by virtue of their thermophilic nature and some morphological features [4]. The genus Rhizomucor, as monographed by Schipper [4], contains two well-known species ( $R$. miehei and $R$. pusillus) that are thermophilic in nature and can grow at temperatures of $50^{\circ} \mathrm{C}$ or above [5].

Thermophilic fungi are important producers of thermostable enzymes that can be used in industrial high- 
temperature bioprocesses [3,6]. For a long time, $R$. miehei as a thermophilic fungus has been used mainly as a producer of industrial proteases and lipases [6-9]. The aspartic protease produced by $R$. miehei has been widely used as a calf chymosin substitute in industrial cheese making [7,9]. The lipases from $R$. miehei are well studied and commercially available in both soluble and immobilized forms with very high activities and good stabilities [6,8]. Other extracellular enzymes from $R$. miehei have been characterized but have not been used commercially including fibrinolytic enzyme, $\beta$-glucanase and xylanase [10-12]. Despite their potential industrial values, most members of the genus Rhizomucor remain poorly characterized [13].

Currently, a few hundreds of fungal genomes have been sequenced, including important human pathogens, plant pathogens and model organisms [14-20]. The genome of Industry-related fungi, like Aspergillus niger (which is widely used for the production of enzymes) and Trichoderma reesei (an industrial producer of plant biomass hydrolyzing enzymes), have also been sequenced [21,22]. Comparative genomic analyses of three thermophilic ascomycete species, Thermomyces lanuginosus [20], Thielavia terrestris and Myceliophthora thermophila suggest that aside from representing a potential reservoir of thermostable enzymes, thermophilic fungi are amenable to be manipulated using classical and molecular genetics [23]. A thermophilic fungus $R$. miehei strain CAU432, newly isolated from self-heating hay in Henan Province of China, has been found to be a good producer of aspartic proteases and $\beta-1,3-1,4$-glucanase [11]. It exhibits a broad growth temperature ranging from $25-55^{\circ} \mathrm{C}$ and the optimum growth temperature is at $50^{\circ} \mathrm{C}$. R. miehei has industrial potentials due to its abilities of producing extracellular enzymes. To facilitate future investigations, we sequenced the genome of $R$. miehei CAU432. In combination with transcriptome analysis, the mechanisms of thermophilic adaptation in $R$. miehei were investigated for developing potential strategies to massively produce thermostable enzymes.

\section{Results}

\section{General features of the genome}

Using a combination of Roche 454 and Illumina systems (in the Additional file 1: Table S1), the genome of R. miehei was shot-gun sequenced. The final assembly genome size is $27.6 \mathrm{Mb}$, N50 contig length is approximately $188.9 \mathrm{~kb}$ and $\mathrm{N} 90$ contig is in $61.4 \mathrm{~kb}$. Gene prediction was performed using different models, which yielded 10,345 protein-coding genes with an average length of 1,621 bp (Table 1). Total size of the genome is consistent with the estimation of approximately 27 to $29 \mathrm{Mb}$ from 10 separated chromosomes between 0.55 to $5.8 \mathrm{Mb}$ by pulsed field gel electrophoresis (PFGE) (Figure 1). The $R$. miehei genome (27.6 Mb) falls within
Table 1 Properties of the R. miehei CAU432 genome

\begin{tabular}{ll}
\hline Genome & Value \\
\hline Scaffolds/contigs ( $\geq 500$ bp) & 471 \\
Contig N50 (bp) & 188,961 \\
Contig N90 (bp) & 61,458 \\
Mean (bp) & 19,849 \\
Max (bp) & 619,110 \\
Nuclear genome assembly size $\left(\mathrm{Mb}^{\boldsymbol{a}}\right)$ & 27.6 \\
$\mathrm{G}+\mathrm{C}$ content (\%) overall & 43.8 \\
$\mathrm{G}+\mathrm{C}$ content (\%) coding & 47.4 \\
G + C content (\%) in introns & 38.12 \\
Protein coding gene number & 10,345 \\
Mean gene length (bp) & 1,621 \\
Percent coding (\%) & 47.1 \\
Exons & 52,179 \\
Mean number per gene & 5.0 \\
Mean length (bp) & 249.23 \\
Introns & 41,834 \\
Mean number per gene & 4.462 \\
Mean length (bp) & 90.0 \\
RNA (tRNA number) & 136 \\
\hline
\end{tabular}

${ }^{a} \mathrm{Mb}$, mega base pairs.

the size of most available fungal genomes that has a range of $10-60 \mathrm{Mb}$ with a median of $28 \mathrm{Mb}$ (Table 2). This whole genome information has been deposited at DDBJ/EMBL/GenBank under the accession No. AGBC00000000.

The average $\mathrm{G}+\mathrm{C}$ content of the genome is $43.8 \%$ which is higher than those of zygomycete fungi (average $35.3 \%$ ) but lower than most ascomycete fungi including three thermophilic ascomycetes, T. lanuginosus (52.14\%), T. terrestris (54.7\%) and M. thermophila (51.4\%) (Table 2) [20,23-25]. Since G:C pairs are more thermally stable, it is somewhat surprising that the $\mathrm{G}+\mathrm{C}$ content of thermophilic $R$. miehei whole genome (43.8\%) and its coding genes (47.4\%) are close to those of the mesophilic ascomycetous fungi (Table 2). However, the values are significantly higher than those of the mesophilic zygomycetes such as Rhizopus oryzae, average $35.3 \%$ and $35 \%$ for whole genome and protein coding genes, respectively [26]. The majority of predicted protein-coding genes contain multiple exons, with an average of 5 exons per gene and an average exon length of $249.2 \mathrm{bp}$ (Table 1). Introns are of typical length in fungi, averaging between $80 \mathrm{bp}$ and $150 \mathrm{bp}$ [24]. R. miehei genome contains $0.877 \mathrm{Mb}$ of repetitive sequences representing $3.17 \%$ of the assembled genome (in the Additional file 1: Table S2), which is much lower than that of $R$. oryzae (34.77\%) [26]. The repetitive sequences in the $R$. miehei 


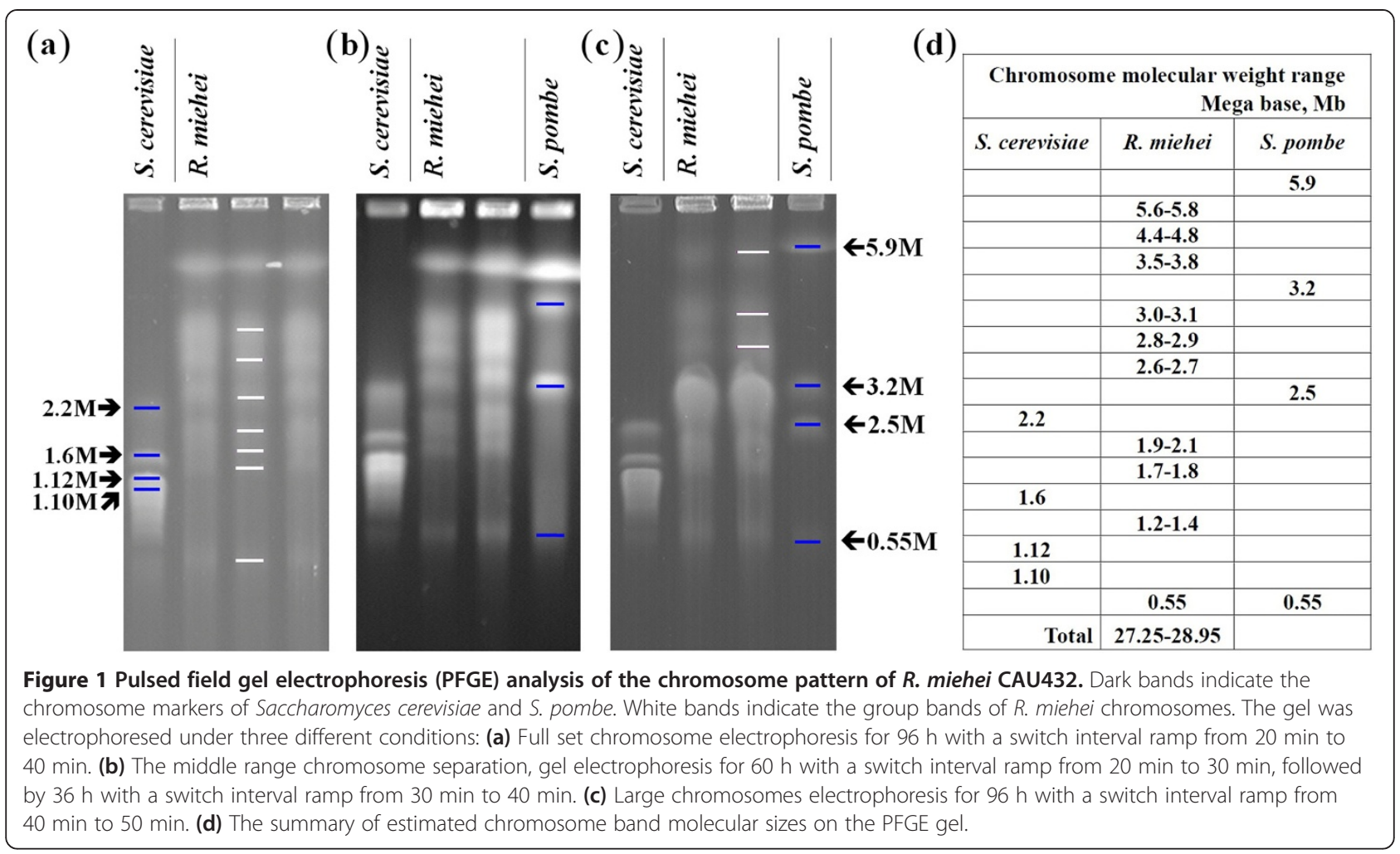

Table 2 General features of some fungal genomes compared with that of $\boldsymbol{R}$. miehei

\begin{tabular}{|c|c|c|c|c|c|}
\hline Organism & Size $\left(\mathrm{Mb}^{a}\right)$ & No. gene (coding) & Percent coding (\%) & $\mathrm{G}+\mathrm{C}$ content $(\%)$ & Reference \\
\hline Aspergillus fumigatus & 29.4 & 9,926 & 50.1 & 49.9 & {$[16]$} \\
\hline A. nidulans & 30.1 & 10,701 & 58.8 & 50.3 & http://www.aspgd.org/ \\
\hline A. niger & 33.9 & 14,165 & - & 50.4 & {$[21]$} \\
\hline Fusarium graminearum & 36.4 & 14,038 & 48.76 & 48.04 & http://www.broadinstitute.org/ \\
\hline Magnaporthe grisea & 37.9 & 11,109 & 40.5 & 51.6 & http://www.broadinstitute.org/ \\
\hline Mucor circinelloides & 36.6 & 11,719 & 36.5 & 34.4 & http://genome.jgi-psf.org/ \\
\hline Myceliophthora thermophila & 38.7 & 9,110 & - & 51.4 & [23] \\
\hline Neurospora crassa & 40.0 & 12,188 & 36.3 & 48.2 & http://www.ncbi.nlm.nih.gov/genome/ \\
\hline Penicillium chrysogenum & 32.2 & 12,943 & 56.6 & 48.9 & http://www.ncbi.nlm.nih.gov/genome/ \\
\hline Phanerochaete chrysosporium & 29.9 & 11,777 & 45 & 57 & {$[15]$} \\
\hline Phycomyces blakesleeanus & 53.9 & 16,528 & 32.4 & 33.2 & http://genome.jgi-psf.org/ \\
\hline Podospora anserina & 36 & 10,545 & 44.75 & 52.02 & {$[17]$} \\
\hline Rhizomucor miehei & 27.6 & 10,345 & 47.1 & 43.83 & This work \\
\hline Rhizopus oryzae & 46.1 & 17,459 & 39 & 35.6 & {$[26]$} \\
\hline Thermomyces lanuginosus & 23.3 & 5,105 & 55.6 & 52.14 & {$[20]$} \\
\hline Thielavia terrestris & 36.9 & 9,813 & - & 54.7 & {$[23]$} \\
\hline Trichoderma reesei & 33.9 & 9,129 & 40.4 & 52 & {$[22]$} \\
\hline
\end{tabular}

${ }^{a} \mathrm{Mb}$, mega base pairs. 
genome consist of recognizable transposable elements (TEs) including short interspersed nuclear elements (SINEs), long interspersed nuclear elements (LINEs), long terminal repeat (LTR) elements and unclassified interspersed repeats.

Of all predicted genes, $71.6 \%$ (7,407 genes) of the translated proteins show sequence similarity to proteins in the known databases, and $57.6 \%$ (5,961 genes) in $R$. miehei CAU432 can be annotated and attributed into different functional categories in Gene Ontology (GO) (Figure 2a). Compared to other three zygomycete fungi, $R$. miehei encodes a larger number of proteins with GO terms involved in protein binding group, electron carriers and transcription regulators in the molecular function category (Figure $2 \mathrm{~b}$ ).

\section{Phylogenetic and syntenic relationships}

The order of Mucorales consists of genera such as Mucor, Phycomyces, Rhizopus, and Rhizomucor. However, the phylogenetic relationships among the members of Mucoraceae and other fungi remain unclear. Based on a total of 409 orthologous protein sequences, a phylogenomic tree also placed R. miehei and Phycomyces blakesleeanus in the same clade while $R$. oryzae and Mucor circinelloides in another clade (Figure 3a). A phylogenomic analysis revealed that $R$. miehei and P. blakesleeanus diverged about 248 million years (MY) ago, and $R$. miehei diverged about 468 MY from R. oryzae and M. circinelloides (Figure 3a).

We found that there are 2,306 orthologues shared between $R$. miehei and other zygomycetes, M. circinelloides, $R$. oryzae and P. blakesleeanus. In addition to the common orthologues among $R$. oryzae and P. blakesleeanus, 441 (115 plus 326) shared orthologues were detected between $R$. miehei and $P$. blakesleeanus while only 293 (107 plus 186) between $R$. miehei and $R$. oryzae (Figure $3 \mathrm{~b}$ ). These numbers also suggest that $R$. miehei is closer to P. blakesleeanus than to $R$. oryzae. Syntenic relationship analysis of $R$. miehei with three other Mucorales indicated that a total of 169 syntenic blocks between $R$. miehei and P. blakesleeanus were detected

(a)
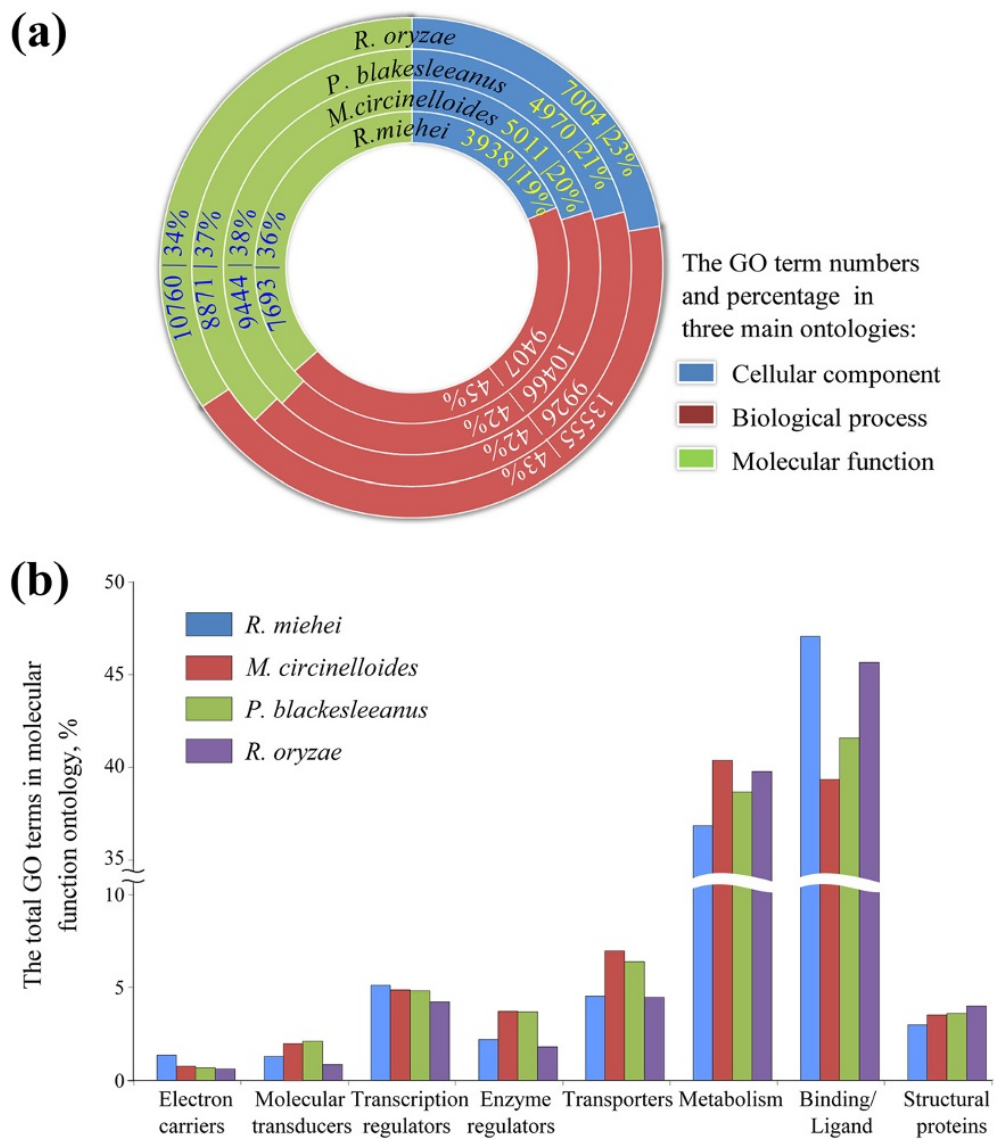

Figure 2 Functional classifications of three zygomycete genomes compared with that of R. miehei CAU432. (a) Comparison of the GO term numbers of R. miehei, M. circinelloides, P. blakesleeanus and R. oryzae in $\mathrm{GO}$ categories. Each circle represents the relative fraction of genes represented in each of the categories for each genome. The gene numbers are also shown. (b) The difference percentage of $G O$ terms in molecular function category by gene ontology. 


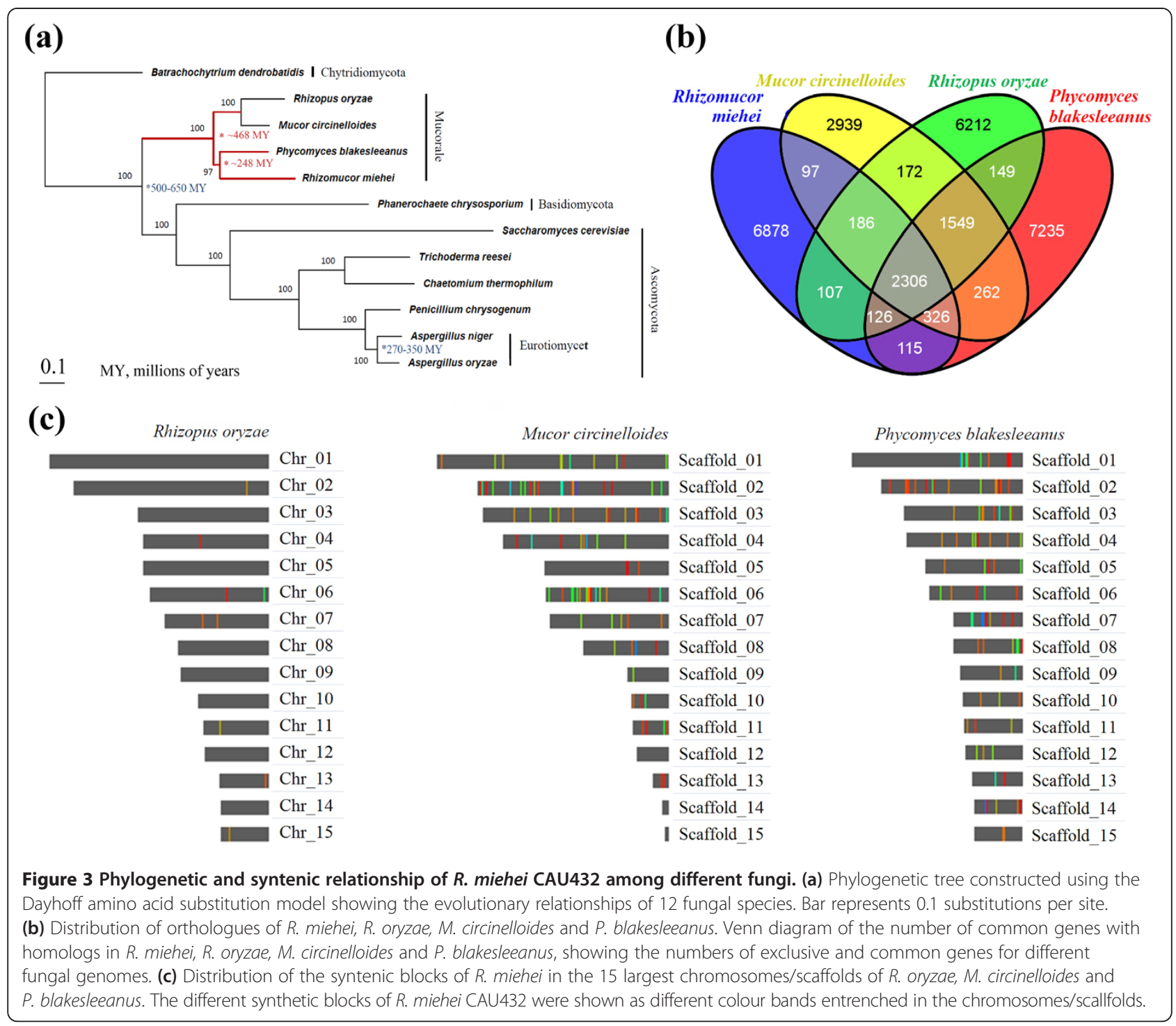

while only 125 and 8 syntenic blocks were identified between $R$. miehei vs. $M$. circinelloides and $R$. miehei vs. $R$. oryzae, respectively (Figure 3c). These observations hence support the view that the genomic sequences of $R$. miehei are closer to P. blakesleeanus than to M. circinelloides and $R$. oryzae.

Our Pfam analysis identified 1,827 protein families (containing 3,979 proteins) in $R$. miehei, more than in $M$. circinelloides $(1,804$ families containing 4,682 proteins) and $R$. oryzae (1,683 families containing 6,076 proteins). A stochastic birth-and-death model [27] showed that relative to the most recent common ancestor of $R$. oryzae and $M$. circinelloides, 31 families including glycoside hydrolase $(\mathrm{GH})$ families, phenol hydroxylase, metallopeptidase, lipase and transporter were expanded while 70 families (lipase, chitin synthase, Hsp70 protein, peptidase, transporter and transposase) were contracted in R. miehei (in the Additional file 1: Table S3).

\section{Carbohydrate-active enzymes in Rhizomucor miehei and} other fungi

Carbohydrate-Active Enzymes (CAZys) participate in many important biological processes including cell wall synthesis, signaling and energy production. Our analysis found 110 glycoside hydrolases (GHs), 118 glycosyl transferases (GTs), 2 polysaccharide lyases (PLs), 20 carbohydrate esterases (CEs), and 20 carbohydrate binding modules (CBMs) in the genome of $R$. miehei (Table 3). Comparatively, lower numbers of GHs, PLs, CEs and CBMs were identified in $R$. miehei than in other fungi. In contrast, a higher number of GTs was identified (in the Additional file 1: Tables S4-S8). Comparative analysis identified CBM12, GH8, GH46, GT10, GT64 and GT77 unique to $R$. miehei except $R$. oryzae [26]. Relative to other fungi, the genome of $R$. miehei was particularly enriched with the GH families of GH15, GH31, GH36, GH37 and GH46, and GT families of GT2, GT15, GT49, GT62, 
Table 3 Comparison of the number of CAZymes of $R$. miehei with those of other fungi ${ }^{a}$

\begin{tabular}{|c|c|c|c|c|c|c|}
\hline Species & GH & GT & PL & CE & CBM & Total \\
\hline Aspergillus nidulans FGSC A4 & 251 & 92 & 19 & 30 & 41 & 433 \\
\hline A. niger CBS 513.88 & 243 & 118 & 8 & 23 & 43 & 435 \\
\hline A. oryzae RIB40 & 294 & 116 & 21 & 30 & 34 & 495 \\
\hline Leptosphaeria maculans v23.1.3 & 225 & 95 & 19 & 34 & 51 & 424 \\
\hline Magnaporthe grisea 70-15 & 232 & 92 & 4 & 46 & 65 & 439 \\
\hline Neurospora crassa OR74A & 174 & 76 & 3 & 22 & 42 & 317 \\
\hline Penicillium chrysogenum Wisconsin_54-1255 & 216 & 102 & 9 & 22 & 49 & 398 \\
\hline Phanerochaete chrysosporium & 182 & 66 & 4 & 16 & 48 & 316 \\
\hline Podospora anserina S mat+ & 226 & 87 & 7 & 41 & 97 & 458 \\
\hline Rhizomucor miehei CAU432 & 110 & 118 & 2 & 20 & 20 & 270 \\
\hline Rhizopus oryzae RA 99-880 & 118 & 143 & 6 & 39 & 27 & 333 \\
\hline
\end{tabular}

${ }^{a}$ Enzymes abbreviated based on CAZyme classification. GH, glycoside hydrolase; GT, glycosyl transferase; PL, polysaccharide lyase; CE, carbohydrate esterase; CBM, carbohydrate-binding module.

GT64, and GT77. A CE family of CE4 and a PL family of PL14 were also found in the fungus (in the Additional file 1: Tables S4-S8).

\section{Proteases}

Proteolysis is ubiquitous in fungi, and is essential for protein degradation, amino acid assimilation and cellular differentiation. A total of 155 proteases (proteolytic enzymes or proteinases) were found in $R$. miehei CAU432, including 140 peptidases and/or proteases, and 15 proteosome and ubiquitin related proteases. $R$. miehei contains a unique collection of proteases (in the Additional file 2: Figure S1, in the Additional file 1: Table S9). Forty three of 155 predicted peptidases contain secreted signal peptides. Comparatively, the number of peptidases in the $R$. miehei genome is slightly higher than that of previously reported for A. fumigatus (136 peptidases), A. oryzae (134 peptidases) [28] and T. terrestris (143 peptidases) [23], but lower than that of $A$. nidulans (210 peptidases) and $A$. niger (169 peptidases). Also, the number of secreted peptidases is higher than that of other thermophilic fungi and fungal pathogens $[18,23]$.

\section{Lipases and esterases}

Lipases (triacylglycerol acylhydralases; EC 3.1.1.3) and esterases (carboxylic ester hydrolases; EC 3.1.1.1) collectively known as lipolytic enzymes are important industrial enzymes for biocatalysis, biorefining, food processing, the chiralspecific synthesis of pharmaceuticals and fungal toxin degradation due to their ability to catalyze many different reactions based on hydrolysis and synthesis of esters formed from glycerol and long-chain fatty acids $[8,13,29,30]$. The $R$. miehei genome contains a diverse array of genes that encode ester bond hydrolysis enzymes. Ninety seven genes belong to lipases, phospholipase and thiolester hydrolases (EC 3.1.-. -) while only
40 genes are glycerol ester hydrolases including the main group of "true" lipases, triacylglycerol lipase. Twenty nine genes belong to "true" phospholipase genes, lysophospholipase (EC 3.1.1.5) and 24 genes being thiolester and sulfuric-ester hydrolases (EC 3.1.2/6.-). Other ester bonds hydrolases are phosphorus-containing anhydrides (including other part of EC 3.1.- and all EC 3.6.-) consisting of 157 genes in total. There are 43 protein phosphatase genes in R. miehei CAU432 genome. The main type protein phosphatase genes are serine/threonine protein phosphatase and protein tyrosine phosphatase (EC 3.1.3.-).

\section{Cellulolytic enzymes}

Cellulose degradation is achieved through the synergistic action of cellulases (endoglucanases), cellobiohydrolases (exoglucanases) and cellobiosidases ( $\beta$-glucosidases). Specifically, there are four endoglucanases and eight $\beta$ glucosidases in the genome. Fungal cellobiohydrolases are classified in the families of GH6 and GH7 while $\beta$ glucosidases constitutes a major group among glycosidehydrolyzing enzymes belonging to families $\mathrm{GH} 1$ and GH3. No genes belonging to families GH1, GH6 and GH7 were found in the R. miehei genome. Only eight GH3 family genes were identified in $R$. miehei in contrast to those filamentous ascomycetes typically containing more than ten genes (in the Additional file 1: Table S4 ). Otherwise, the $R$. miehei genome contains two putative endoglucanases (typical cellulose-degrading enzymes) assigned to the family GH45, which carry the sole CBM1 module. We also found two putative GH9 proteins (in the Additional file 1: Table S4), a family of endoglucanases mostly found in bacteria, plants, and occasionally in animals [31]. GH9 members are absent in most of ascomycete filamentous fungi but are also found in $R$. oryzae (in the Additional file 1: Table S4). The role of fungal GH9 remains unclear, 
but is probably unrelated to cellulose degradation [32]. Two mannan-degrading enzymes in family GH5 may be responsible for mannan digestion. A new glycoside hydrolase was identified in $R$. miehei, which belongs to the family GH125 of exo- $\alpha-1,6$-mannosidases that contains one member from Streptococcus pneumoniae (SpGH125) and the other one from Clostridium perfringens (CpGH125) [33].

\section{Transcriptomes of the R. miehei CAU432}

The transcriptional profiles of $R$. miehei CAU432 grown at two different temperatures $\left(30^{\circ} \mathrm{C}\right.$ and $\left.50^{\circ} \mathrm{C}\right)$ were investigated by RNA-seq analysis (in the Additional file 2: Figure S2a). Approximately 35 million high-quality reads were generated from each library, and $62 \%$ reads were uniquely mapped to the genome (in the Additional file 2: Figure S2a). A high percentage of reads (67.1\%) were mapped to predicted protein-coding genes, while $3.96 \%$ reads were distributed in splice junctions, 3.49\% reads in antisense transcripts, $2.27 \%$ in introns, and $21.9 \%$ in other genomic regions (in the Additional file 2: Figure S2b). The frequency of reads which mapped to different genes ranged from one to over 300,000 (in the Additional file 2: Figure S2a and S2c).

The expression profiles of $R$. miehei at $30^{\circ} \mathrm{C}$ and $50^{\circ} \mathrm{C}$ were compared using the DEGseq program (in the Additional file 2: Figure S2d). More than $90 \%$ of predicted genes $\left(9,680,93.0 \%\right.$ at $30^{\circ} \mathrm{C} ; 9,618,93.6 \%$ at $\left.50^{\circ} \mathrm{C}\right)$ were detected with at least one read, while 128 genes and 190 genes were uniquely expressed at $50^{\circ} \mathrm{C}$ and $30^{\circ} \mathrm{C}$, respectively (in the Additional file 2: Figure S3a). The results show that 2,117 genes were differently expressed $(P<0.001)$ by the fungus with more than two-fold changes (in the Additional file 2: Figure S3b and Figure S4). There were 849 up-regulated and 1,268 down-regulated genes in mycelia grown at $50^{\circ} \mathrm{C}$ (in the Additional file 2: Figure S4). These genes included ribosomal proteins, heat shock proteins, translation elongation factors, which involved in the protein synthesis. In contrast, the expression of proteasome subunits associated with the degradation of proteins decreased significantly (in the Additional file 2: Figure S4). These observations implicate that both increasing the production and decreasing the degradation of proteins can be further explored for industrial usage for $R$. miehei mycelia grown at $50^{\circ} \mathrm{C}$. Many genes of the GHs, lipases and phospholipases were expressed at low expression levels in the mycelia grown at both $30^{\circ} \mathrm{C}$ and $50^{\circ} \mathrm{C}$ (Additional file 2: Figure S3b). Furthermore, most of the proteolytic enzymes exhibited a decreased expression level when the growth was shifted from $30^{\circ} \mathrm{C}$ to $50^{\circ} \mathrm{C}$ (in the Additional file 2: Figure S3b). These differently expressed genes fall into 31 Gene Ontology groups (in the Additional file 2: Figure S5). Of note, more up-regulated genes were annotated with $\mathrm{GO}$ terms of macromolecular complex and organelle part groups in cellular component category when the cells grew at $50^{\circ} \mathrm{C}$ compared to cells grown at $30^{\circ} \mathrm{C}$.

\section{Discussion}

We report here a genomic analysis of $R$. miehei, one of the most widely used extracellular enzyme producers. The phylum Zygomycota contains approximately 900 species of true fungi. So far, over a hundred of fungal genomes have been sequenced and are publicly available. However, Zygomycetes have been rarely investigated both genetically and genomically. Results from this study suggest that $R$. miehei is closer to P. blakesleeanus than to M. circinelloides and $R$. oryzae, although Rhizomucor, Mucor and Rhizopus are classified under the same family Mucoraceae. $R$. miehei is well known for its capacity to produce large amounts of hydrolytic enzymes such as protease, lipase in industry. Here, we focus on a potential reservoir of thermostable enzymes from $R$. miehei.

Complete degradation of starch requires the combined action of three main types of amylases: $\alpha$-amylase, glucoamylase and $\alpha$-glucosidase. It is known that GH13 (including EC 3.2.1.1 $\alpha$-amylase), GH15 (including EC 3.2.1.3 glucoamylase) and GH31 (including EC 3.2.1.20 $\alpha$ glucosidase) are involved in amylolysis [34]. All three main amylases are present in multiple copies in the $R$. miehei genome. Specifically, there are six GH13, seven GH15 and eight GH31 enzymes identified in the genome. Of note, $R$. miehei contains the higher number (seven) of family GH15 enzymes for starch degradation, compared to the other fungal genomes (in the Additional file 1: Table S4).

Chitinolytic enzymes can be divided into chitinases (EC 3.2.1.14) and $N$-acetylglucosaminidases (EC 3.2.1.52). Chitinases are members of families GH18 and GH19. $\mathrm{N}$-acetylglucosaminidases belong to families $\mathrm{GH} 3$ and GH20. The genomes of filamentous fungi typically contain between 10 and 25 different chitinases [23,35]. In R. miehei, a total of $13 \mathrm{GH} 18$ genes and three GH20 genes were found, a value similar to what is found in known ascomycete and basidiomycete species (in the Additional file 1: Table S4). A gene of GH18 (RhzM07326) contains three CBM5 which has been found in bacterial enzymes and may bound weakly to several crystalline polysaccharides, while another one (RhzM00912) contains one CBM19 with chitin-binding function (in the Additional file 1: Table S7). Three genes belonging to GH20 are identified in the R. miehei genome and are possibly related to $\beta-N$-acetylhexosaminidases (EC 3.2.1.52). Unlike dikaryotic fungi, the cell wall of Mucorales usually contains a high percentage of chitin and chitosan which are synthesized by chitin synthases and chitin deacetylases [26]. Indeed, there are evidences that chitin and chitosan are an integral part of the cell wall structure and chitosan is a component of mycelia in $R$. miehei [36]. Family CE9 
which includes $N$-acetylglucosamine-6-phosphate deacetylases (EC 3.5.1.25) is important for the metabolism of chitin. R. miehei contains one CE9 member (in the Additional file 1: Table S7), similar to ascomycete and basidiomycete fungi. Chitin deacetylase (EC 3.5.1.41) as one of the members of family CE4, hydrolyzes the acetamido group in the $N$-acetylglucosamine units of chitin and chitosan, leading to the production of glucosamine units and acetic acid. In $R$. miehei, a very large set of chitin deacetylases of family CE4 is found (in the Additional file 1: Table S7). Most of the previously reported chitin deacetylases often exist in multiple isoforms [37]. A total of 16 CE4 genes were found in $R$. miehei which is only second to the previous highest number of CE4 observed in the Rhizopus oryzae [26].

In the $R$. miehei genome, there was a high number of serine endopeptidases (EC 3.4.21.-), aspartic endopeptidases (EC 3.4.23.-), metalloendopeptidases (EC 3.4.24.-), and threonine endopeptidases (EC 3.4.25.1) which belongs to proteasome proteolytic subunits. For omega peptidases, only two ubiquitin-specific peptidases (EC 3.4.19.12) were found. As Aspergillus oryzae is known to have prominent potential for the secretory production of various enzymes [38], comparison of peptidase gene numbers between $R$. miehei and A. oryzae is shown in the Additional file 1: Table S9. The gene numbers of 36 serine endopeptidases, 18 aspartic endopeptidases, 33 metalloendopeptidases and 14 threonine endopeptidases are strikingly larger than those for $A$. oryzae (in the Additional file 1: Table S9). The large number of predicted peptidase genes is consistent with previous studies describing $R$. miehei as one of the best protease producers among the fungi $[7,9]$. $R$. miehei CAU432 has 18 genes encoding aspartic protease, only one (RhzM08045) has been so far cloned, characterized and has reached commercial product (Accession no. M18411) [36]. The aspartic proteinase from $R$. miehei (RMP) has a very high thermal stability, which is probably due to the high level of glycosylation [39]. N-linked carbohydrates enhance the thermal stability of glycoproteins. The corresponding gene has $2 \mathrm{~N}$-glycosylation sites. Actually, most of other aspartic proteinase genes from $R$. miehei possess also multiple $N$-glycosylation sites. Thus, various aspartic proteinases from $R$. miehei may exhibit excellently thermal stability among aspartic proteinases.

Lipases and esterases are water-soluble enzymes that hydrolyze ester bonds of water-insoluble substrates such as triglycerides, phospholipids, and cholesteryl esters. Fungal lipases show remarkable levels of activity and stability in non-aqueous environments and are widely used in the catalysis of unnatural reactions such as esterification and transesterification [39]. R. miehei is also known to be a good producer of lipolytic enzymes [6,8]. Although only one lipase gene which corresponds to the gene (RhzM08505) has been isolated and characterized from R. miehei (Accession no. B34959) [40] to date, there are 31 lipase genes in the genome (in the Additional file 2: Figure S6b). The number of lipases in the $R$. miehei genome (in the Additional file 2: Figure S1) is higher than those of most of fungi [23], and the number of secreted lipases ( 9 in $R$. miehei) is above the average found in other fungi [19]. Besides, $R$. miehei has a large number of phospholipase genes (21 genes), and the number of secreted phospholipases is higher than that of human fungal pathogens such as Malassezia globosa, Malassezia restricta [41].

Thermophilic fungi can grow at elevated temperatures above $50^{\circ} \mathrm{C}$ [3]. Thermotolerance is critical for $R$. miehei to grow at high temperature ranges characteristic of original ecological habitat niche. Heat shock proteins (HSPs), chaperones, ubiquitin and proteasome related misfolding protein degradation are highly related to heat stress response by regulating many cellular processes [42-44]. Over expression of HSP70 in Trichoderma was evidenced to enhance fungal resistance to heat and other abiotic stresses [45]. HSP60, belonging to the intercompartmental transport proteins is thought to be important in thermophily for thermophilic fungi, was found to be highly expressed in the mycelia of $R$. miehei CAU432 at $50^{\circ} \mathrm{C}$. Chaperones can mediate nascent protein folding, which is fundamentally important from thermophilic bacteria to plant $[46,47]$. In the $R$. miehei genome, there are 122 chaperone genes including Heat shock protein families, DnaJ, GrpE, HSP factors, peptidyl-prolyl cis-trans isomerase and other specific chaperones.

Proteasome activator complex subunit 4, proteasome subunits and chaperone regulatory proteins were significantly down-regulated at the high growth temperature. F-Box/WD-box proteins, RING finger proteins and ankyrins, together with limited cullins, the positive regulators of SCF-dependent ubiquitylation and subsequent protein degradation $[43,48]$, all showed an increased expression when the culture of $R$. miehei was shifted to the high temperature (in the Additional file 2: Figure S4). These observations suggest that the protein synthesis and fate play important roles for $R$. miehei CAU432 to grow under temperature stress. Two related protein modification systems (viz. neddylation and sumoylation), whose proteins were designated as ubiquitin-like proteins (UBLs) which play a role in DNA damage repair under heat stress $[49,50]$. However, UBL proteins in $R$. miehei remain at low level of expression at both growth conditions compared to chaperone/ubiquitin/proteasome systems in the genome. Apart from the HSPs and DnaJ chaperones, peptidyl-prolyl cis-trans isomerase, T-complex proteins, UBX domain-containing proteins, rotamases (FK506 binding protein) [51] and vacuolar transporter chaperones were highly induced at high temperature (in the Additional file 2: Figure S4). 
Non-reducing disaccharide trehalose, having the unique property of stabilizing membranes and enzymes against drying and thermal denaturation, accumulates upon heat, cold or osmotic stress [52]. Trehalose-phosphatase is the enzyme in charge of final release of trehalose. In the $R$. miehei genome, three trehalose-phosphatases (EC 3.1.3.12) and three trehalose-6-phosphate synthases (EC 2.4.1.15) were identified. These genes were expressed at high levels when cells were grown at $50^{\circ} \mathrm{C}$. Of the trehalose synthesis pathway genes in $R$. miehei, five trehalases were found and two of them (RhzM00608 and RhzM03618) expressed at high levels at $50^{\circ} \mathrm{C}$. The trehalase genes of RhzM01862 and RhzM07090 showed stable expression at both low and high temperatures. Compared to $R$. oryzae which contains three trehalose related genes [26], the fact that $R$. miehei has many more genes expressed at high temperature, suggests that trehalose plays an important role in the growth of mycelia at $50^{\circ} \mathrm{C}$.

\section{Conclusion}

The draft genome and transcriptome of $R$. miehei were investigated for the first time. We developed the fundamental genomic and molecular resources for characterization of $R$. miehei. $R$. miehei as a thermophilic fungus contains a large collection of genes for degrading its natural substrates, for coping different ecological conditions, and for mediating various stress during thermophilic growth. Based on the existence of a large repertoire of amylolytic, proteolytic and lipolytic genes in the genome, $R$. miehei has potential in the production of a variety of such enzymes.

\section{Methods}

\section{Strains and genomic DNA preparation}

$R$. miehei CAU432 used in the study (deposited at China General Microbiological Culture Collection Center under CGMCC No. 4967) was isolated from a pile of high-temperature hay due to anaerobic respiration in Sanmenxia city of Henan province, China. R. miehei CAU432 was maintained on potato dextrose-agar (PDA) plate as described by Tang et al. [11]. The strain was grown in rich medium (2\% oat flour, 1\% tryptone, $1 \%$ yeast extract, $5 \% \quad \mathrm{KH}_{2} \mathrm{PO}_{4}, 0.3 \% \quad \mathrm{MgSO}_{4} \cdot 7 \mathrm{H}_{2} \mathrm{O}, 0.3 \%$ $\mathrm{CaCl}_{2}$ ) at $50^{\circ} \mathrm{C}$ for 2 days in a shaker with a rotation speed of $200 \mathrm{rpm}$. Genomic DNA of $R$. miehei CAU432 was prepared from mycelia disrupted with pestle and mortar in liquid nitrogen. The genomic DNA was further purified by phenol-chloroform extraction as described by Sambrook and Russell [53].

\section{Pulsed field gel electrophoresis (PFGE)}

Chromosomal DNA of $R$. miehei CAU432 was prepared as described by Orbach et al. [54]. Sporangiospores of R. miehei CAU432 obtained from young slant cultures were germinated in a complete medium (containing $0.1 \%$ yeast extract, $0.5 \%$ tryptone, $1 \%$ glucose) at $43^{\circ} \mathrm{C}$, followed with isolation of germline protoplasts for chromosome analysis. Chromosomal DNA was prepared in agarose plugs with the CHEF Genomic DNA Plug kit (BioRad) following the instructions of the manufacturer. A 0.6\% agarose gel in $0.5 \times$ modified TBE $(0.1 \mathrm{M}$ Tris, $0.1 \mathrm{M}$ Boric acid, $0.2 \mathrm{mM}$ EDTA) was used to separate the chromosomes. Chromosome gel electrophoresis of contour-clamped homogeneous electric field (CHEF) was performed using the CHEF Mapper XA Pulsed Field Electrophoresis System (Bio-Rad) in 0.6\% UltraPure ${ }^{\mathrm{TM}}$ agarose (Invitrogen) gels at $16^{\circ} \mathrm{C}$ in circulating $0.5 \times \mathrm{TBE}$ buffer, $1.5 \mathrm{~V} / \mathrm{cm}$ with different pulse intervals for $96 \mathrm{~h}$. After separation, gels were stained in $0.5 \mu \mathrm{g} / \mathrm{ml}$ ethidium bromide for $1 \mathrm{~h}$ and then photographed under UV illumination.

\section{Genome sequencing and assembly}

The sequencing of the genome of $R$. miehei CAU432 was performed using single-end reads from a fragment library and also using pair-end reads from two mate-pair libraries. The fragment library was sequenced according to Roche GS FLX Titanium Sequencing Method Manual. Approximately $16 \times$ genome coverage was obtained from fragment library. Two mate-pair libraries with insertion sizes of $2-3 \mathrm{~kb}$ and $6-10 \mathrm{~kb}$ were constructed and sequenced according to the manufacturer's instructions (Illumina).

All of Roche 454 reads were assembled into 5,730 contigs using the software Newbler 2.3. The pair-end (both termini from the same DNA fragment) reads from 2$3 \mathrm{~kb}$ and $6-10 \mathrm{~kb}$ libraries were used to connect the assembled contigs, starting with short insert library and followed by iterating the scaffolding process, using longer insert library. A total of 1,522 intra-scaffold gaps were filled using the paired-end information to retrieve 454 reads whose ends were well-aligned on the adjacent contigs.

\section{Genome annotation and analysis}

The tRNAs were identified using the software tRNAscanSE-1.23. rRNAs were detected by using the software RNAmmer-1.2. Repetitive sequences in the $R$. miehei genome were identified by using RepeatModeler-1.0.4 (http://www.repeatmasker.org/RepeatModeler.html) and were classified according to the classification criteria in the RepBase database (http://www.girinst.org/repbase/ index.html). The resulting 38 families of repeats were added into the search library in RepeatMasker to find the repetitive sequences in the $R$. miehei genome [55].

ORFs were firstly predicted on all contigs by MAKER2.10 software which combines the information of the gene structure based on the results produced from the TopHat software that maps RNA-seq reads against genomic sequences of $R$. miehei CAU432, with the gene 
structure information predicted from AUGUSTUS [56] (trained on sequences of Rhizopus oryzae) and GeneMarkES version 1.0. Secondly, genes were selected only if the predicted protein lengths were more than 50 amino acids or 30 amino acids with BLAST evidence. Thirdly, for the regions without any MAKER prediction, non-overlapping gene models (supported with blast hits of $\geq 60 \%$ average identity and $\geq 80 \%$ query coverage) were picked; otherwise, the GeneMark-ES prediction was preferred. The final predictions of protein-coding genes were checked individually according to the BLAST evidence. Predicted genes were named as the abbreviated organism (RhzM) followed by a five-digit number. All the protein-coding genes were functionally assigned by homology to annotated genes from the NCBI nonredundant database, and Uniprot database and classified according to Gene Ontology (GO) and KEGG metabolic pathways. Secretory proteins were predicted by SignalP 3.0 Server at http://www.cbs.dtu.dk/services/SignalP/. Membrane proteins were predicted by TMHMM Server v. 2.0 at http://www.cbs.dtu.dk/services/TMHMM/.

\section{Construction of phylogenetic tree and detection of synteny blocks}

Ortholog conservation in fungi was characterized with by OrthoMCL [57]. In total, 409 orthologous proteins were acquired and aligned with MUSCLE v3.8.31 [58]. A maximum likelihood phylogenomic tree was created using the concatenated amino acid sequences with the program TREE-PUZZLE using the Dayhoff model [59]. The divergence time between species was estimated with the Langley-Fitch method with r8s [60] by calibrating against the reassessed origins of the Ascomycota and Eurotiomycetes (at 500-650 and 270-350 million years (MY) ago, respectively) [61]. The protein families of the 12 fungi were identified by Pfam analysis with script pfam_scan.pl (ftp://ftp.sanger.ac.uk/pub/databases/Pfam/ Tools) against the Pfam database (ftp://ftp.sanger.ac.uk/ pub/databases/Pfam/current_release) [62]. The gene expansion and extraction of $R$. miehei relative to the most recent common ancestor of $R$. oryzae and $M$. circinelloides was analyzed with CAFE software using a stochastic birth and death model [27]. Single copy of orthologous groups of $R$. miehei were used to detect syntenic blocks among $R$. miehei, $R$. oryzae and $M$. circinelloides using the software OrthoCluster [63].

\section{Identification of carbohydrate-active enzymes in fungal proteomes}

Annotation of carbohydrate-active genes was performed using the CAZy annotation pipeline [64]. The identification of genes that code for carbohydrate-active enzymes (GH, Glycoside Hydrolase; GT, glycosyltransferase; PL, polysaccharide lyase and $\mathrm{CE}$, carbohydrate esterase) and their associated carbohydrate-binding module (CBM) in fungi was performed using CAZy database (http://www. cazy.org). Briefly, sequences of the proteins in CAZy were first divided by their constitutive modules (catalytic modules, carbohydrate binding module and other noncatalytic modules). Each $R$. miehei protein sequence was compared by the BLAST analysis against the library of around 50,000 individual modules. Protein sequences with an e-value $<0.1$ were individually analyzed by multiple sequence alignment and search of conserved signatures/motifs. Each protein was also compared to a library of experimentally characterized proteins found in CAZy for functional description.

\section{Transcriptome analysis}

For isolation of RNA, $50 \mathrm{ml}$ of fresh rich medium were inoculated with $1 \%\left(50^{\circ} \mathrm{C}\right)$ or $5 \%\left(30^{\circ} \mathrm{C}\right)$ of 2 days old seeds to uniform the growth phase. Mycelia of $R$. miehei CAU432 after incubation at $30^{\circ} \mathrm{C}$ or $50^{\circ} \mathrm{C}$ for 1 day were ground to fine powder with liquid nitrogen prior to extraction. Total RNA was extracted using the Trizol reagent (Invitrogen, Carlsbad, US) and poly(A) mRNA was purified on oligo $\mathrm{d}(\mathrm{T})$ conjugated magnetic beads using FastTrack MAG mRNA Isolation Kits (Invitrogen, USA) according to the manufacturer's protocol. The purified mRNA was fragmented, ligated with $\mathrm{SOLiD}^{\mathrm{TM}}$ adaptor mix and reversely transcribed by using $\mathrm{SOLiD}^{\mathrm{Tm}}$ Total RNA-Seq Kit according to the manufacturer's protocol. The constructed RNA-seq libraries were subjected to single end sequencing using Applied Biosystems SOLiD sequencing platforms. High quality reads were obtained after removing raw SOLiD reads with median QV (quality value) below 13 .

Forty-five base pair (bp) long sequences were obtained from the termini of each exon read to construct the splice junction database. Fifty bp long RNA-seq reads were mapped to $R$. miehei assembled genome with the software Corona_Lite_Plus_4.2.1 (Applied Biosystems) at 5 mismatches while the unmapped reads were mapped to the splice junction database. In the order of first $45 \mathrm{bp}$ (at 4 mismatches), $40 \mathrm{bp}$ (at 4 mismatches), $35 \mathrm{bp}$ (at 3 mismatches) and $30 \mathrm{bp}$ (at 3 mismatches) sequences obtained from unmapped reads were iteratively mapped to genome and splice junction database. Reads with multiple alignments were discarded. Differentially expressed gene under two growth temperatures were identified using the DEGseq software [65] by the following criteria: $P<0.001$ and normalized fold change of comparing two temperatures being greater more than 1 or less than -1 .

\section{Availability of supporting data}

The Rhizomucor miehei CAU432 whole genome sequence has been submitted to GenBank and deposited at DDBJ/ EMBL/GenBank under the accession No. AGBC00000000 
(http://www.ncbi.nlm.nih.gov/nuccore/AGBC00000000). The version described in this paper is the first version, AGBC01000000. The RNA-seq data have been deposited at NCBI Short Read Archive under series accession No. SRP008125 (http://www.ncbi.nlm.nih.gov/sra/?term= SRP008125) for the samples of $R$. miehei CAU432 growing at $30^{\circ} \mathrm{C}$ and $50^{\circ} \mathrm{C}$, respectively. The sequence and annotation data are also available at http://foodenzyme.cau. edu.cn/data_base/index.html. These include genome sequence, datasets for genes and proteins, a summary of the results from Pfam analyses and a Blast server.

\section{Additional files}

Additional file 1: Table S1. Libraries used for the R. miehei CAU432 genome sequencing. Table S2. Transposable Elements (TEs) in the R. miehei CAU432 genome. Table S3. Expanded (highlighted in green) and contracted (highlighted in yellow) protein families in R. miehei CAU432. Table S4. Comparison of the number of GHs of R. miehei CAU432 with those of other fungi. Table S5. Comparison of the number of GTs of $R$. miehei CAU432 with those of other fungi. Table S6. Comparison of the number of PLs of R. miehei CAU432 with those of other fungi. Table S7. Comparison of the number of CEs of $R$. miehei CAU432 with those of other fungi. Table S8. Comparison of the number of CBMs of $R$. miehei CAU432 with those of other fungi. Table $\mathbf{S 9 .}$ Numbers of peptidase genes in $R$. miehei and Aspergillus oryzae.

Additional file 2: Figure S1. Location of various enzymes in $R$. miehei CAU432. Figure S2. RNA-seq analysis of $R$. miehei transcriptome from mycelia growing at $30^{\circ} \mathrm{C}$ and $50^{\circ} \mathrm{C}$. Figure $\mathbf{S 3}$. Gene expression in R. miehei CAU432 mycelia grown at $30^{\circ} \mathrm{C}$ (labeled as T30) and $50^{\circ} \mathrm{C}$ (labeled as T50). Figure S4. Gene expression changes in mycelia of R. miehei CAU432 growth at $50^{\circ} \mathrm{C}$ comparing with that of growth at $30^{\circ} \mathrm{C}$. Figure S5. Molecular functions of Gene Ontology for differently expressed genes with at least two-fold changes between two growth temperatures in R. miehei CAU432.

\section{Competing interests}

The authors declare that they have no competing interests.

\section{Authors' contributions}

$B Z, G Z$ and ZD assembled and finished the genome sequence, processed the raw data and performed shotgun assembly and contig scaffolding, manually curated the computer-generated annotation, and analyzed the annotation. PZ and YT isolated RNA and DNA, performed the 454/Roche sequencing and made libraries and prepared Figures 1,2 and 3. SC performed all post-shotgun assembly bioinformatics aspects of the study, assisted in gap closure and in determining sequence accuracy. QY, SY and CC wrote parts of the main manuscript. BH participated and supervised the CAZy annotation. ZJ designed and coordinated the study, and wrote parts of the manuscript. All authors read and approved the final manuscript.

\section{Acknowledgements}

This research was supported by the National Science Fund for Distinguished Young Scholars (Project No. 31325021) and National Natural Science Foundation of China (Project No. 31371718). The funders had no role in study design, data collection and analysis, decision to publish, or preparation of the manuscript. We also thank Guogua Xiao for his technical assistance in gene family evolution and Dongmei Tian for her technical assistance in transcriptome analysis.

\section{Author details}

${ }^{1}$ Department of Biotechnology, College of Food Science and Nutritional Engineering, China Agricultural University, Beijing 100083, China. ${ }^{2}$ Core Genomic Facility, Beijing Institute of Genomics, Chinese Academy of Sciences, Beijing 100101, China. ${ }^{3}$ UMR 7257 - Centre National de la Recherche Scientifique \& Aix-Marseille Université, Marseille 13288, France.
${ }^{4}$ Department of Biological Sciences, King Abdulazziz University, Jeddah, Saudi Arabia. ${ }^{5}$ Bioresource Utilization Laboratory, College of Engineering, China Agricultural University, Beijing 100083, China. ${ }^{6}$ Office of Bioinformatics and Center for Molecular Studies, 113 Gregor Mendel Circle Greenwood, SC 29646, USA.

Received: 5 December 2013 Accepted: 9 April 2014 Published: 21 April 2014

\section{References}

1. Mora C, Tittensor DP, Adl S, Simpson AG, Worm B: How many species are there on Earth and in the ocean? PLOS Biol 2011, 9:e1001127.

2. Hibbett DS, Binder M, Bischoff JF, Blackwell M, Cannon PF, Eriksson OE, Huhndorf S, James T, Kirk PM, Lucking R, Thorsten Lumbsch H, Lutzoni F, Matheny PB, McLaughlin DJ, Powell MJ, Redhead S, Schoch CL, Spatafora JW, Stalpers JA, Vilgalys R, Aime MC, Aptroot A, Bauer R, Begerow D, Benny GL, Castlebury LA, Crous PW, Dai YC, Gams W, Geiser DM, et al: A higher-level phylogenetic classification of the Fungi. Mycol Res 2007, 111:509-547.

3. Morgenstern I, Powlowski J, Ishmael N, Darmond C, Marqueteau S, Moisan MC, Quennevillea G, Tsang A: A molecular phylogeny of thermophilic fungi. Fungal Biol 2012, 116:489-502.

4. Schipper MAA: On the genera Rhizomucor and Parasitella. Stud Mycol 1978, 17:53-71.

5. de Hoog GS, Guarra J, Gené J, Figueras MJ: Atlas of clinical fungi. 2nd edition. Utrecht, The Nederlands; Reus, Spain: Centralbureau voor Schimmelcultures; Universitat Rovira i Virgili; 2000.

6. Maheshwari R, Bharadwaj G, Bhat MK: Thermophilic fungi: their physiology and enzymes. Microbiol Mol Biol Rev 2000, 64:461-488.

7. Rao MB, Tanksale AM, Ghatge MS, Deshpande W: Molecular and biotechnological aspects of microbial proteases. Microbiol Mol Biol Rev 1998, 62:597-635.

8. Rodrigues RC, Fernandez-Lafuente R: Lipase from Rhizomucor miehei as an industrial biocatalyst in chemical process. J Mol Catal B: Enzymatic 2010, 64:1-22.

9. Harboe MK: Rhizomucor miehei aspartic proteinases having improved properties. Adv Exp Med Biol 1998, 436:293-296.

10. Ali UF, Ibrahim ZM: Production and some properties of fibrinolytic enzyme from Rhizomucor miehei (Cooney \& Emerson) Schipper. J Appl Sci Res 2008, 4:892-899.

11. Tang $Y$, Yang $S$, Yan $Q$, Zhou P, Cui J, Jiang Z: Purification and characterization of a novel $\beta-1,3-1,4-$ glucanase (lichenase) from thermophilic Rhizomucor miehei with high specific activity and its gene sequence. J Agric Food Chem 2012, 60:2354-2361.

12. Fawzi EM: Highly thermostable purified xylanase from Rhizomucor miehei NRRL 3169. Ann Microbiol 2010, 60:363-368.

13. Liu Y, Xu H, Yan Q, Yang S, Duan X, Jiang Z: Biochemical characterization of a first fungal esterase from Rhizomucor miehei showing high efficiency of ester synthesis. PLOS ONE 2013, 8:e77856.

14. Galagan JE, Calvo SE, Borkovich KA, Selker EU, Read ND, Jaffe D, FitzHugh W, Ma LJ, Smirnov S, Purcell S, Rehman B, Elkins T, Engels R, Wang S, Nielsen CB, Butler J, Endrizzi M, Qui D, lanakiev P, Bell-Pedersen D, Nelson MA, Werner-Washburne M, Selitrennikoff CP, Kinsey JA, Braun EL, Zelter A, Schulte $U$, Kothe GO, Jedd G, Mewes W, et al: The genome sequence of the filamentous fungus Neurospora crassa. Nature 2003, 422:859-868.

15. Martinez D, Larrondo LF, Putnam N, Gelpke MD, Huang K, Chapman J, Helfenbein KG, Ramaiya P, Detter JC, Larimer F, Coutinho PM, Henrissat B, Berka R, Cullen D, Rokhsar D: Genome sequence of the lignocellulose degrading fungus Phanerochaete chrysosporium strain RP78. Nat Biotechnol 2004, 22:695-700.

16. Nierman WC, Pain A, Anderson MJ, Wortman JR, Kim HS, Arroyo J, Berriman M, Abe K, Archer DB, Bermejo C, Bennett J, Bowyer P, Chen D, Collins M, Coulsen R, Davies R, Dyer PS, Farman M, Fedorova N, Fedorova N, Feldblyum TV, Fischer R, Fosker N, Fraser A, Garcia JL, Garcia MJ, Goble A, Goldman GH, Gomi K, Griffith-Jones S, et al: Genomic sequence of the pathogenic and allergenic filamentous fungus Aspergillus fumigatus. Nature 2005, 438:1151-1156.

17. Espagne E, Lespinet $O$, Malagnac F, Da Silva C, Jaillon O, Porcel BM, Couloux A, Aury JM, Segurens B, Poulain J, Anthouard V, Grossetete S, Khalili H, Coppin E, Dequard-Chablat M, Picard M, Contamine V, Arnaise S, Bourdais A, Berteaux-Lecellier V, Gautheret D, de Vries RP, Battaglia E, Coutinho PM, Danchin EG, Henrissat B, Khoury RE, Sainsard-Chanet A, Boivin A, 
Pinan-Lucarre B, et al: The genome sequence of the model ascomycete fungus Podospora anserina. Genome Biol 2008, 9:R77.

18. Khoshraftar S, Hung S, Khan S, Gong Y, Tyagi V, Parkinson J, Sain M, Moses AM, Christendat D: Sequencing and annotation of the Ophiostoma ulmi genome. BMC Genomics 2013, 14:162

19. Gao Q, Jin K, Ying SH, Zhang Y, Xiao G, Shang Y, Duan Z, Hu X, Xie XQ, Zhou G, Peng G, Luo Z, Huang W, Wang B, Fang W, Wang S, Zhong Y, Ma LJ, St Leger RJ, Zhao GP, Pei Y, Feng MG, Xia Y, Wang C: Genome sequencing and comparative transcriptomics of the model entomopathogenic fungi Metarhizium anisopliae and M. acridum. PLoS Genet 2011, 7:e1001264

20. McHunu NP, Permaul K, Abdul Rahman AY, Saito JA, Singh S, Alam M: Xylanase superproducer: Genome sequence of a compost-loving thermophilic fungus, Thermomyces lanuginosus strain SSBP. Genome Announc 2013, 1:e00388-13.

21. Pel HJ, de Winde JH, Archer DB, Dyer PS, Hofmann G, Schaap PJ, Turner G, de Vries RP, Albang R, Albermann K, Andersen MR, Bendtsen JD, Benen JA, van den Berg M, Breestraat S, Caddick MX, Contreras R, Cornell M, Coutinho PM, Danchin EG, Debets AJ, Dekker P, van Dijck PW, van Dijk A, Dijkhuizen L, Driessen AJ, d'Enfert C, Geysens S, Goosen C, Groot GS, et al: Genome sequencing and analysis of the versatile cell factory Aspergillus niger CBS 513.88. Nat Biotechnol 2007, 25:221-231.

22. Martinez D, Berka RM, Henrissat B, Saloheimo M, Arvas M, Baker SE, Chapman J, Chertkov O, Coutinho PM, Cullen D, Danchin EG, Grigoriev IV, Harris P, Jackson M, Kubicek CP, Han CS, Ho I, Larrondo LF, de Leon AL, Magnuson JK, Merino S, Misra M, Nelson B, Putnam N, Robbertse B, Salamov AA, Schmoll M, Terry A, Thayer N, Westerholm-Parvinen A, et al: Genome sequencing and analysis of the biomass-degrading fungus Trichoderma reesei (syn. Hypocrea jecorina). Nat Biotechnol 2008, 26:553-560.

23. Berka RM, Grigoriev IV, Otillar R, Salamov A, Grimwood J, Reid I, Ishmael N, John T, Darmond C, Moisan MC, Henrissat B, Coutinho PM, Lombard V, Natvig DO, Lindquist E, Schmutz J, Lucas S, Harris P, Powlowski J, Bellemare A, Taylor D, Butler G, de Vries RP, Allijn IE, van den Brink J, Ushinsky S, Storms R, Powell AJ, Paulsen IT, Elbourne LD, et al: Comparative genomic analysis of the thermophilic biomass-degrading fungi Myceliophthora thermophila and Thielavia terrestris. Nat Biotechnol 2011, 29:922-927.

24. Galagan JE, Henn MR, Ma LJ, Cuomo CA, Birren B: Genomics of the fungal kingdom: insights into eukaryotic biology. Genome Res 2005, 15:1620-1631.

25. Amlacher S, Sarges P, Flemming D, van Noort V, Kunze R, Devos DP, Arumugam M, Bork P, Hurt E: Insight into structure and assembly of the nuclear pore complex by utilizing the genome of a eukaryotic thermophile. Cell 2011, 146:277-289.

26. Ma L, Ibrahim AS, Skory C, Grabherr MG, Burger G, Butler M, Elias M, Idnurm A, Lang BF, Sone T, Abe A, Calvo SE, Corrochano LM, Engels R, Fu J, Hansberg W, Kim JM, Kodira CD, Koehrsen MJ, Liu B, Miranda-Saavedra D, O'Leary S, Ortiz-Castellanos L, Poulter R, Rodriguez-Romero J, Ruiz-Herrera J, Shen YQ, Zeng Q, Galagan J, Birren BW, et al: Genomic analysis of the basal lineage fungus Rhizopus oryzae reveals a whole-genome duplication. PLoS Genet 2009, 5:e1000549.

27. de Bie T, Cristianini N, Demuth JP, Hahn MW: CAFE: a computational tool for the study of gene family evolution. Bioinformatics 2006, 22:1269-1271.

28. Kobayashi T, Abe K, Asai K, Gomi K, Juvvadi PR, Kato M, Kitamoto K, Takeuchi M, Machida M: Genomics of Aspergillus oryzae. Biosci Biotechnol Biochem 2007, 71:646-670.

29. Bornscheuer UT: Microbial carboxyl esterases: classification, properties and application in biocatalysis. FEMS Microbiol Rev 2002, 26:73-81.

30. Sangeetha R, Arulpandi I, Geetha A: Bacterial lipases as potential industrial biocatalysts: An overview. Res J Microbiol 2011, 6:1-24.

31. Ni J, Takehara $\mathrm{M}$, Watanabe $\mathrm{H}$ : Identification of activity related amino acid mutations of a GH9 termite cellulase. Bioresour Technol 2010, 101:6438-6443.

32. Battaglia E, Benoit I, van den Brink J, Wiebenga A, Coutinho PM, Henrissat B, de Vries RP: Carbohydrate-active enzymes from the zygomycete fungus Rhizopus oryzae: a highly specialized approach to carbohydrate degradation depicted at genome level. BMC Genomics 2011, 12:38.

33. Gregg K, Zandberg WF, Hehemann JH, Whitworth GE, Deng L, Vocadlo DJ, Boraston AB: Analysis of a new family of widely distributed metal-independent a-mannosidases provides unique insight into the processing of $N$-linked glycans. J Biol Chem 2011, 286:15586-15596.

34. Yuan XL, Kaaij RM, Hondel CA, Punt PJ, Maarel MJ, Dijkhuizen L, Ram AF: Aspergillus niger genome-wide analysis reveals a large number of novel alpha-glucan acting enzymes with unexpected expression profiles. Mol Genet Genomics 2008, 279:545-561.

35. Seidl V: Chitinases of filamentous fungi: a large group of diverse proteins with multiple physiological functions. Fungal Biol Rev 2008, 22:36-42.

36. Tajdini F, Amini MA, Nafissi-Varcheh N, Faramarzi MA: Production, physiochemical and antimicrobial properties of fungal chitosan from Rhizomucor miehei and Mucor racemosus. Int J Biol Macromol 2010, 47:180-183.

37. Zhao Y, Park RD, Muzzarelli RA: Chitin deacetylases: properties and applications. Mar Drugs 2010, 8:24-46.

38. Yang J, Teplyakov A, Quail JW: Crystal structure of the aspartic proteinase from Rhizomucor miehei at 2.15 A resolution. J Mol Biol 1997, 268:449-459.

39. Mateos Diaz JC, Rodríguez JA, Roussos S, Cordova J, Abousalham A, Carriere F, Baratti J: Lipase from the thermotolerant fungus Rhizopus homothallicus is more thermostable when produced using solid state fermentation than liquid fermentation procedures. Enzyme Microb Technol 2006, 39:1042-1050.

40. Boel E, Huge-Jensen B, Christensen M, Thim L, Fiil NP: Rhizomucor miehei triglyceride lipase is synthesized as a precursor. Lipids 1988, 23:701-706

41. Xu J, Saunders CW, Hu P, Grant RA, Boekhout T, Kuramae EE, Kronstad JW, Deangelis YM, Reeder NL, Johnstone KR, Leland M, Fieno AM, Begley WM, Sun Y, Lacey MP, Chaudhary T, Keough T, Chu L, Sears R, Yuan B, Dawson TL: Dandruff-associated Malassezia genomes reveal convergent and divergent virulence traits shared with plant and human fungal pathogens. Proc Natl Acad Sci U S A 2007, 104:18730-18735.

42. Sørensen JG, Kristensen TN, Loeschcke V: The evolutionary and ecological role of heat shock proteins. Ecology Lett 2003, 6:1025-1037.

43. Nielsen MM, Overgaard J, Sørensen JG, Holmstrup M, Justesen J, Loeschcke $\checkmark$ : Role of HSF activation for resistance to heat, cold and hightemperature knock-down. J Insect Physiol 2005, 51:1320-1329.

44. Lechner E, Achard P, Vansiri A, Potuschak T, Genschik P: F-box proteins everywhere. Curr Opin Plant Biol 2006, 9:631-638.

45. Montero-Barrientos M, Hermosa R, Cardoza RE, Gutiérrez S, Monte E: Functional analysis of the Trichoderma harzianum nox 1 gene, encoding an NADPH oxidase, relates production of reactive oxygen species to specific biocontrol activity against Pythium ultimum. Appl Environ Microbiol 2011, 77:3009-3016.

46. Hartl FU, Hayer-Hartl M: Molecular chaperones in the cytosol: from nascent chain to folded protein. Science 2002, 295:1852-1858.

47. Liberek K, Lewandowska A, Ziętkiewicz S: Chaperones in control of protein disaggregation. EMBO J 2008, 27:328-335

48. Mercer AA, Fleming SB, Ueda N: F-box-like domains are present in most poxvirus ankyrin repeat proteins. Virus Genes 2005, 31:127-133.

49. Huang TT, D'Andrea AD: Regulation of DNA repair by ubiquitylation. Nat Rev Mol Cell Biol 2006, 7:323-334.

50. Voellmy R, Boellmann F: Chaperone regulation of the heat shock protein response. Adv Exp Med Biol 2007, 594:89-99.

51. Orozco M, Tirado-Rives J, Jorgensen WL: Mechanism for the rotamase activity of FK506 binding protein from molecular dynamics simulations. Biochemistry 1993, 32:2864-12874.

52. Colaco C, Sen S, Thangavelu M, Pinder S, Roser B: Extraordinary stability of enzymes dried in trehalose: simplified molecular biology. Biotechnol (NY) 1992, 10:1007-1011.

53. Sambrook J, Russell DW: Molecular cloning: a laboratory manual. 3rd edition. New York, USA: Cold Spring Harbor Laboratory Press; 2001.

54. Orbach MJ, Vollrath D, Davis RW, Yanofsky C: An electrophoretic karyotype of Neurospora crassa. Mol Cell Biol 1988, 8:1469-1473.

55. Tarailo-Graovac M, Chen N: Using RepeatMasker to identify repetitive elements in genomic sequences. Curr Protoc Bioinform 2009, 4(4):10.

56. Stanke M, Keller O, Gunduz I, Hayes A, Waack S, Morgenstern B: AUGUSTUS: ab initio prediction of alternative transcripts. Nucleic Acids Res 2006, 34:W435-439.

57. Li L, Stoeckert CJ Jr, Roos DS: OrthoMCL: identification of ortholog groups for eukaryotic genomes. Genome Res 2003, 13:2178-2189.

58. Edgar RC: MUSCLE: multiple sequence alignment with high accuracy and high throughput. Nucleic Acids Res 2004, 32:1792-1797.

59. Schmidt HA, Strimmer K, Vingron M, von Haeseler A: TREEPUZZLE: maximum likelihood phylogenetic analysis using quartets and parallel computing. Bioinformatics 2002, 18:502-504. 
60. Sanderson MJ: r8s: inferring absolute rates of molecular evolution and divergence times in the absence of a molecular clock. Bioinformatics 2003, 19:301-302.

61. Taylor JW, Berbee ML: Dating divergences in the Fungal Tree of Life: review and new analyses. Mycologia 2006, 98:838-849.

62. Finn RD, Mistry J, Tate J, Coggill P, Heger A, Pollington JE, Gavin OL, Gunasekaran P, Ceric G, Forslund K, Holm L, Sonnhammer ELL, Eddy SR, Bateman A: The Pfam protein families database. Nucleic Acids Res 2010 38:D211-222.

63. Vergara IA, Chen N: Large synteny blocks revealed between Caenorhabditis elegans and Caenorhabditis briggsae genomes using OrthoCluster. BMC Genomics 2010, 11:516.

64. Cantarel BL, Coutinho PM, Rancurel C, Bernard T, Lombard V, Henrissat B: The Carbohydrate-Active EnZymes database (CAZy): An expert resource for Glycogenomics. Nucleic Acids Res 2009, 37:D233-D238.

65. Wang L, Feng Z, Wang X, Wang X, Zhang X: DEGseq: an R package for identifying differentially expressed genes from RNA-seq data. Bioinformatics 2010, 26:136-138.

doi:10.1186/1471-2164-15-294

Cite this article as: Zhou et al:: Genome sequence and transcriptome analyses of the thermophilic zygomycete fungus Rhizomucor miehei. BMC Genomics 2014 15:294.

\section{Submit your next manuscript to BioMed Central and take full advantage of:}

- Convenient online submission

- Thorough peer review

- No space constraints or color figure charges

- Immediate publication on acceptance

- Inclusion in PubMed, CAS, Scopus and Google Scholar

- Research which is freely available for redistribution 